\title{
Calcium homeostasis in second trimester fetuses
}

\author{
CF MONIZ,* KH NICOLAIDES, C TZANNATOS, ${ }^{*}$ CH RODECK
}

From the *Department of Chemical Pathology, and the Harris Birthright Research Centre for Fetal Medicine, King's College School of Medicine and Dentistry, London

SUMMARY The concentrations of ionised calcium ions $\left(\mathrm{Ca}^{++}\right)$, total calcium, parathyroid hormone, $\mathrm{pH}$, total protein, albumin, sodium, and potassium were measured in paired fetal and maternal blood from pregnancies at 15 to 24 weeks' gestation. Pure fetal blood samples were obtained fetoscopically.

The concentrations of fetal ionised calcium ions $(n=26)$; mean (SD) $1.33(0 \cdot 12) \mathrm{mmol} / 1(5 \cdot 32$ $(0.48) \mathrm{mg} / 100 \mathrm{ml})$ and those of parathyroid hormone $(\mathrm{n}=9) ; 68(19) \mathrm{pmol} / 1(58(16) \mu \mathrm{g} / 100 \mathrm{ml})$ were significantly higher than those of the mothers: $1.18(0.09) \mathrm{mmol} / 1(4.7(0.4) \mathrm{mg} / 100 \mathrm{ml})$, and $40 \mathrm{pmol} / 1(<34 \mu \mathrm{g} / 100 \mathrm{ml})$, respectively. There was no difference between measured fetal and maternal total calcium, $\mathrm{pH}$, and electrolytes. The fetal total protein and albumin concentrations increased with gestation but were always lower than the equivalent maternal values. The calculated total calcium was $0.23-0.45 \mathrm{mmol} / 1(0.9-1.8 \mathrm{mg} / 100 \mathrm{ml})$ higher in the fetal than in maternal blood from the same pregnancy. There were no fetal arteriovenous differences in ionised calcium ions despite higher venous $\mathrm{pH}$.

Calcium metabolism in the pregnant woman and her fetus is a complex process with several intricate and interrelated components. ${ }^{1}$ As long ago as 1923, Boget and Plass reported that the total serum calcium in the fetus was higher than that of the mother. ${ }^{2}$ This observation was subsequently confirmed and elaborated on by other investigators, who found that both total and ionised calcium were higher in the fetus. ${ }^{3-6}$ Data on parathyroid hormone concentrations in the fetus are contradictory, being reported as either low, ${ }^{7}$ normal, ${ }^{8}$ or high. ${ }^{9}$ Reports on calcitonin concentrations are sparse and equally contradictory. ${ }^{6}$

All existing data, however, are derived from studies on animals, or in man, from blood samples obtained from the umbilical cord at the time of delivery. The technique of fetoscopy, which is used for the diagnosis and treatment of various fetal conditions, ${ }^{10}$ has given us the unique opportunity to obtain pure fetal blood from second trimester pregnancies (as early as 15 weeks' gestation) and to study the calcium homeostasis in the unstressed normal fetus in utero.

\section{Patients and methods}

Fetal and maternal blood, $1 \mathrm{ml}$ and $5 \mathrm{ml}$, respectively, were obtained from 36 pregnancies undergoing diagnostic fetoscopy at 15 to 24 weeks' gestation. The data used for the determination of the reference val-

Accepted for publication 5 March 1986 ues were derived from pregnancies in which the diagnostic outcome was normal. Pure fetal blood samples were obtained by umbilical cord puncture under direct vision through an Olympus Selfoscope that was introduced transabdominally into the amniotic cavity. ${ }^{11-13}$ Either arterial or venous blood was taken; in five cases paired arterial and venous samples were obtained. One millilitre of fetal blood was sufficient for the diagnostic investigation, and the additional sample required for this study did not increase the fetal risk. The maternal samples were obtained from the antecubital vein without venous stasis.

The samples were collected in sodium heparin saturated with calcium chloride (580 heparin, Radiometer Ltd) to a final concentration of $17-50 \mathrm{IU} / \mathrm{ml}$. Whole blood was analysed immediately for ionised calcium and $\mathrm{pH}$, by using an ion selective electrode (ICA 1 Radiometer, Cohenhagen). The samples were then centrifuged at $500 \mathrm{~g}$ for 10 minutes and the plasma analysed within four hours of collection. The maintenance schedule for the electrode system included a daily calibration with aqueous standards CAL 1 and CAL 2 (Radiometer Ltd) and a one point calibration with CAL 1 before introducing the samples. The sensitivity of the calcium electrode was accepted when the theoretical Nerst response was between 0.90 and 1.05 . The $\mathrm{pH}$ electrode was very stable and showed no drift.

Quality control for the ICA 1 Radiometer was performed using aqueous controls, Qualicheck Low and 
Table 1 Methods and performance of assays

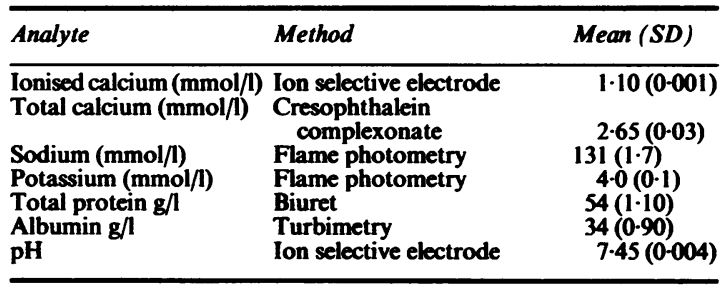

High (Radiometer Ltd) propriety and external quality assurance was achieved by participation in the three monthly external quality control scheme run by Radiometer Ltd. Total calcium, total protein, sodium, and potassium were determined by analysis of the plasma on a multichannel continuous flow analyser (SMAC, Technicon, Basingstoke). Table 1 shows the methods used and the performance obtained. The albumin was measured on a CobasBio centrifugal analyser (Roche Diagnostica, Welwyn Garden City, Hertfordshire, United Kingdom). The accuracy of the methods was monitored by comparing the results of the UK External Quality Assurance Scheme (UKEQAS) with the mean value obtained by the assay.

In nine cases parathyroid hormone was assayed using a mid molecule assay (PTH-MM, Immunonuclear Inc), in which the antibody is sensitive to the 46-68 amino acid region of human parathyroid hormone. The standards are calibrated with several
Table 2 Concentration of analytes in fetal and maternal blood

\begin{tabular}{|c|c|c|}
\hline \multirow[t]{2}{*}{ Analyte } & Maternal blood & Fetal blood \\
\hline & $\operatorname{Mean}(S D)$ & $\operatorname{Mean}(S D)$ \\
\hline $\begin{array}{l}\text { Ionised calcium (mmol/l) } \\
\text { Total calcium (mmol/l) } \\
\text { Sodium (mmol/l) } \\
\text { Potassium (mmol/l) } \\
\text { Total protein } \mathrm{g} / \mathrm{l} \\
\text { Albumin } \mathrm{g} / \mathrm{l} \\
\text { pH }\end{array}$ & $\begin{array}{cl}1 \cdot 18(0.09) \\
2.17(0.08) \\
135 \quad(1.3) \\
3.5 & (0.9) \\
62 & (3.00) \\
34 & (2.60) \\
7.41 & (0.03)\end{array}$ & $\begin{array}{cl}1.33 & (0 \cdot 12) \\
2.27 & (0 \cdot 13) \\
135 & (1 \cdot 7) \\
3.4 & (1.0) \\
34 & (3 \cdot 50) \\
19 & (3.70) \\
7.38 & (0.04)\end{array}$ \\
\hline
\end{tabular}

reference preparations, including World Health Organisation 79/500. The coefficient of variation between and within assay was never more than $8.9 \%$.

\section{Results}

Table 2 shows the fetal and maternal blood concentrations (mean (SD)) of total calcium, ionised calcium, total protein, albumin, sodium, and potassium, and the figure shows the individual values of ionised calcium and parathyroid hormone. There was no difference between the sodium or potassium concentrations of the two compartments. Of all the substances measured, the only one that showed a significant change with gestation in the gestational range studied, was albumin in fetal blood (albumin = 0.97 gestation +0.79 ; correlation coefficient $=0.57$,
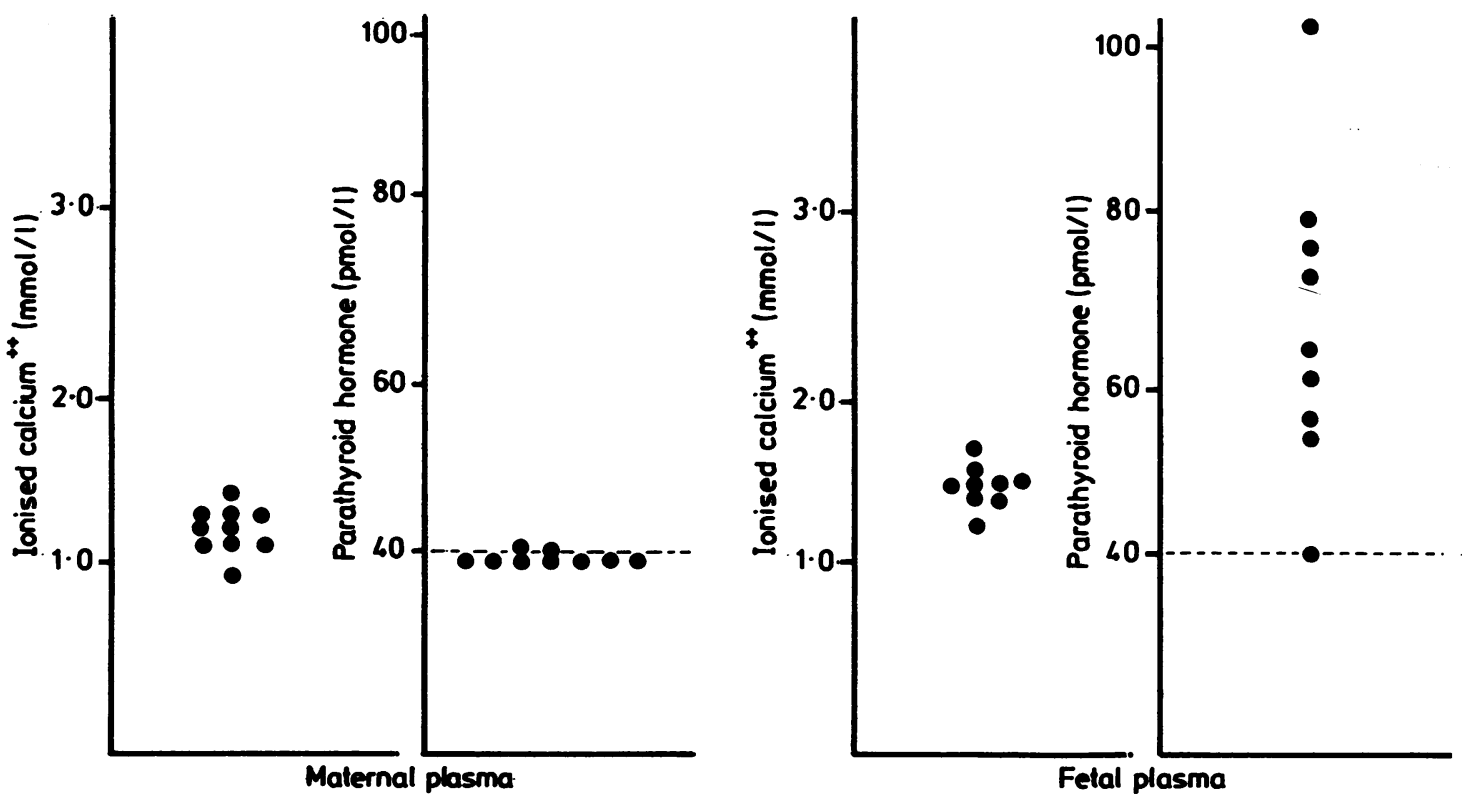

Concentrations of ionised calcium (CA ${ }^{++}$) and parathyroid hormone (PTH) in fetal and maternal plasma. Detection limit of immunoreactive porathyroid hormone. 
Table 3 Calcium and $p H$ values in umbilical artery and vein

\begin{tabular}{llll}
\hline Blood sample & Total calcium $(\mathrm{mmol} / \mathrm{l})$ & Ionised calcium $(\mathrm{mmol} / \mathrm{l})$ \\
\hline Umbilical vein & $2 \cdot 27(0 \cdot 19)$ & $1 \cdot 34(0 \cdot 11)$ & $7 \cdot 36(0 \cdot 05)$ \\
Umbilical artery & $2 \cdot 30(0 \cdot 16)$ & $1 \cdot 34(0 \cdot 10)$ & $7 \cdot 31(0 \cdot 05)$ \\
Maternal vein & $2 \cdot 20(0 \cdot 09)$ & $1 \cdot 20(0-04)$ & $7 \cdot 34(0 \cdot 04)$ \\
\hline
\end{tabular}

$\mathrm{p}<0.005)$.

Although the ionised calcium was higher in fetal than in maternal blood from the same pregnancy (Student's paired $t$ test; $t=2.7, \mathrm{p}<0.05$ ), there was no significant difference in the measured total calcium (Table 2). The calculated total calcium, however (taking into account the lower fetal albumin), was $0.23-0.45 \mathrm{mmol} / 1(0.9-1.8 \mathrm{mg} / 100 \mathrm{ml})$ higher in fetal than in maternal blood from the same pregnancy. The calculated ionised calcium, using the algorithm of MacCleans and Hastings, ${ }^{14}$ which incorporates the measured total calcium, $\mathrm{pH}$, and proteins was also higher in the fetal compartment, indicating that fetal plasma proteins have similar binding characteristics to adult plasma proteins.

Table 3 shows the ionised calcium and $\mathrm{pH}$ in the five paired umbilical arterial and venous samples. Although the venous $\mathrm{pH}$ was higher (Student's paired $t$ test; $t=8.7, \mathrm{p}<0.001)$, there was no difference between measured ionised calcium $(t=0 \cdot 75$, not significant).

The fetal parathyroid hormone was higher than that of the mothers's (Student's paired $t$ test; $t=3 \cdot 4$, $\mathrm{p}<0.05)$.

\section{Discussion}

In this study a normal range of variables relating to calcium homeostasis was established in samples obtained fetoscopically from fetuses in the second trimester of pregnancy. The results confirm the findings of experiments on animals and previous studies on samples obtained at the time of delivery. ${ }^{451415}$ Thus in both the second and third trimesters of intrauterine life the fetus exhibits relative hypercalcaemia. Moreover, by measuring the protein and electrolyte concentrations in fetal and maternal blood, we showed that there was good agreement between the measured and derived ionised calcium concentrations in the two compartments.

Studies on animals suggest that the placental transfer of calcium entails both active and passive processes $^{1617}$ and results in the net intrauterine accumulation of $25-30 \mathrm{~g}$, which is mostly incorporated in the fetal skeleton. We found no fetal arteriovenous difference between the measured ionised calcium, but when the correction for the $\mathrm{pH}$ gradient, which exists between the two vessels, was incorporated, the venous samples were hypercalcaemic, indicating a net pla- cental transfer of calcium to the umbilical venous blood of $0 \cdot 1 \mathrm{mmol} / 1(0 \cdot 14 \mathrm{mg} / 100 \mathrm{ml})$.

In contrast to calcium, parathyroid hormone does not cross the placenta. ${ }^{1819}$ The fetal parathyroid gland contains detectable hormone from 10 weeks onwards. ${ }^{20}$ Our findings of paradoxically high fetal parathyroid hormone values, despite relative hypercalcaemia, support the hypothesis that the release of hormones in utero is regulated by some means other than that of the calcium concentration. ${ }^{21}$ Indeed, discrepant results between bioactive and immunoreactive parathyroid hormone in cord blood ${ }^{22}$ suggest a changed structure and function correlation for this hormone in fetal life when compared with that of adults. Experiments on animals, however, have shown a prompt fetal parathyroid hormone response to hypocalcaemia. ${ }^{23}{ }^{24}$ It is therefore more likely that the negative feedback mechanism regulating secretion of parathyroid hormone in utero is set at a higher calcium concentration than in postnatal life.

We thank Mrs V Thurlow, Biochemistry Laboratory, Lewisham Hospital, for carrying out the parathyroid hormone radioimmunoassays.

\section{References}

${ }^{1}$ Pitkin RM. Calcium metabolism in pregnancy: a review. $A m J$ Obstet Gynecol 1975;121:724-37.

2 Bogert LJ, Plass ED. Placental transmission. 1. The calcium and magnesium content of fetal and maternal blood serum. $J$ Biol Chem 1923;56:297-307.

${ }^{3}$ Crawford JS. Maternal and cord blood at delivery. IV. Glucose, sodium, potassium, calcium and chloride. Biol Neonate 1965;8:222-37.

${ }^{4}$ David L, Anast CS. Calcium metabolism in newborn infants. The interrelationship of parathyroid function and calcium, magnesium and phosphorous metabolism in normal, "sick" and hypocalcemic newborns. J Clin Invest 1974;54:287-96.

${ }^{5}$ Schauberger CW, Pitkin RM. Maternal-perinatal calcium relationships. Obstet Gynecol 1979;53:74-6.

${ }^{6}$ Pitkin RM. Endocrine regulation of calcium homeostasis during pregnancy. Clin Perinatol 1983;10:575-92.

${ }^{7}$ Reitz RE, Daane TA, Woods JR, Weinstein RL. Calcium, magnesium, phosphorus and parathyroid hormone interrelationships in pregnancy and newborn infants. Obstet Gynecol 1977;50:701-5.

${ }^{8}$ Tsang RC, Chen IW, Friedman MA. Neonatal parathyroid function: role of gestational age and postnatal age. $J$ Pediatr 1973;83:728-38

${ }^{9}$ Bergman L, Kjellmer I, Selstam U. Calcitonin and parathyroid hormone-Relation to early neonatal hypocalcemia in infants of diabetic mothers. Biol Neonate 1974;24:151-60.

${ }^{10}$ Nicolaides KH, Rodeck CH. Fetoscopy. Br J Hosp Med 1984;31:396-405.

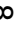
$\infty$ $\infty$

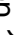

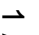

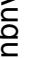
. . œ $\stackrel{\infty}{+}$ 
${ }^{11}$ Rodeck CH, Campbell S. Umbilical cord insertion as a source of pure fetal blood for prenatal diagnosis. Lancet 1979;i:1244-5.

12 Rodeck CH, Campbell S. Sampling pure fetal blood by fetoscopy in the second trimester of pregnancy. Br Med J 1978;ii:728-30.

${ }^{13}$ Rodeck CH, Nicolaides KH. Ultrasound guided invasive procedures in obstetrics. Clin Obstet Gynaecol 1983;10:529-39.

${ }^{14}$ Macleans FC, Hastings AB. The state of calcium in the fluids of the body. J Biol Chem 1935;108:285-322.

${ }^{15}$ Tan CM, Raman A. Maternal fetal calcium relationships in man. $Q J$ Exp Physiol 1972;57:56-9.

${ }^{16}$ Ramberg CF, Delivoria-Papadopoulos M, Crandall EJ, et al. Kinetic analysis of calcium transport across the placenta. J Appl Physiol 1973;35:682-8.

${ }^{17}$ MacDonald NS, Hutchinson DL, Hepler M, Flynn E. Movement of calcium in both directions across the primate placenta. Proc Soc Exp Biol Med 1965;119:476-81.

${ }^{18} \mathrm{Garel} \mathrm{J}$, Dumont C. Distribution and inactivation of labeled parathyroid hormone in the rat fetus. Horm Metab Res 1972;4:217-21.

${ }^{19}$ Northrop G, Misenheimer HR, Becker FO. Failure of parathyroid hormone to cross the non human primate placenta. Am J Obstet Gynecol 1977;129:449-53.
${ }^{20}$ Leroyer-Alizon E, David L, Anast CS, et al. Immunocytological evidence for parathyroid hormone in human parathyroid glands. J Clin Endocrinol Metab 1981;52:513-6.

${ }^{21}$ Schedewie HK, Odell WD, Fisher DA, et al. Parathormone and perinatal calcium homeostasis. Pediatr Res 1979;13:1-6.

${ }^{22}$ Allgrove J, Adami S, Manning RM, O'Riordam JLH. Cytochemical bioassay of parathyroid hormone in maternal and cord blood. Arch Dis Child 1985;60:110-5.

${ }^{23}$ Smith FG Jr, Alexander DP, Buckle RM, Britton G, Nixon DA Parathyroid hormone in foetal and adult sheep: the effect of hypocalcemia. J Endocrinol 1972;53:339-48.

${ }^{24}$ Pitkin RM, Reynolds WA, Williams GA, Kawahara W, Bowman AF, Hargh A. Maternal and fetal parathyroid hormone responsiveness in pregnant primates. $J$ Clin Endocrinol Metab 1980;51:1044-7.

Requests for reprints to: Dr C Moniz, Department of Chemical Pathology, King's College School of Medicine and Dentistry, Denmark Hill, London SE6 8RX, England. 